\title{
FORMULASI DAN UJI SIFAT FISIK SEDIAAN GEL TUNGGAL DAN KOMBINASI EKSTRAK ETANOLIK DAUN SIRIH MERAH (Pipper crocatum) dan MINYAK KAYU MANIS (Cinnamon oil)
}

\author{
Emelda $^{1}$; Saddam Husein ${ }^{1}$;Desi Saputri ${ }^{1}$;olanda ${ }^{1}$
}

${ }^{1}$ Program Studi Sarjana Farmasi, Fakultas IImu-IImu Kesehatan, Universitas Alma Ata

Email : emelda@almaata.ac.id; saddam@almaata.ac.id

\section{Korespondensi:}

Emelda

Program Studi Sarjana Farmasi, Fakultas IImu-IImu Kesehatan, Universitas Alma Ata Email : emelda@almaata.ac.id

\begin{abstract}
Abstrak
Sirih merah memiliki kandungan senyawa aktif seperti minyak atsiri, alkaloid, saponin, tanin dan flavonoid. Minyak atsiri yang terkandung di dalamnya memiliki aktivitas sebagai antiseptik. Tanaman lain yang juga memiliki banyak manfaat adalah kayu manis. Minyak kayu manis diketahui memiliki aktivitas sebagai anti inflamasi. Tujuan dari penelitian ini adalah membuat formulasi sediaan gel kombinasi ekstrak etanol daun sirih merah dan minyak kayu manis dan mengetahui sifat fisik sediaan tersebut. Penelitian ini adalah eksperimental laboratoris. Daun sirih merah diekstraksi dengan pelarut etanol kemudian diformulasikan dalam bentuk gel dan dikombinasikan dengan minyak kayu manis. Uji sifat fisik sediaan krim dan salep, meliputi organoleptik, uji homogenitas, $\mathrm{pH}$ dengan indikator $\mathrm{pH}$ universal, uji daya lekat, daya sebar dan uji konsistensi. Hasil penelitian menunjukkan sediaan gel kombinasi ekstrak etanol daun sirih merah dan minyak kayu manis memiliki warna hijau kecoklatan, dan kayu manis tunggal berwarna putih, memiliki bau khas, berbentuk semipadat, homogen, daya lekat lebih dari 1 detik, daya sebar masih berada dalam rentang 5-7 cm dan uji konsistensi menunjukkan tidak terjadi pemisahan. Sediaan gel kombinasi ekstrak etanol daun sirih merah dan minyak kayu manis memenuhi persyaratan uji fisik, meliputi uji organoleptik, homogenitas, pH, daya lekat daya sebar dan uji konsistensi.
\end{abstract}

Kata Kunci: daun sirih merah; minyak kayu manis; gel; uji sifat fisik

Formulation and Evaluation Gel of Single and Combination of Red Betel Leaf (Pipper crocatum) and Cinnamon Oil

\footnotetext{
Abstract

Red betel contains active compounds such as essential oils, alkaloids, saponins, tannins, and flavonoids. The essential oil contained in it has antiseptic activity. Another plant that also has many benefits is cinnamon. Cinnamon oil is known to have anti-inflammatory activity. The purpose of this study was to formulate a gel preparation for a combination of ethanol extract of red betel leaf and cinnamon oil and to determine the physical properties of these preparations.

This research is an experimental laboratory. Red betel was Extracted with an ethanol solvent, red betel leaves are then formulated in the form of a gel and combined with cinnamon oil. The physical properties test for cream and ointment preparations included organoleptic, homogeneity test, $\mathrm{pH}$ with a universal $\mathrm{pH}$ indicator, adhesion test, spreadability, and consistency test.
} 
Formulasi dan Uji Sifat Fisik Sediaan Gel Tunggal dan Kombinasi Ekstrak Etanolik Daun Sirih Merah (Pipper Crocatum) dan Minyak Kayu Manis (Cinnamon Oil)

The results showed that the combination gel preparation of the ethanol extract of red betel leaf and cinnamon oil had a brownish-green color and white for only cinnamon oil, had a distinctive odor, was semisolid, homogeneous, adhered more than 1 second, the spreadability was still within the range of $5-7 \mathrm{~cm}$ and consistency test showed there is no separation.

The combination gel preparation for the ethanol extract of red betel leaf and cinnamon oil met the physical test requirements, including the organoleptic test, homogeneity, $\mathrm{pH}$, adhesiveness, spreadability, and consistency test.

Keyword: Red Betel leaf, Cinnamon oil, physical properties test

\section{PENDAHULUAN}

Sirih merah (Piper betle Var. Rubrum) merupakan salah satu tanaman yang memiliki potensi dan sudah sejak lama dikenal berkhasiat sebagai penyembuh berbagai penyakit. Sirih merah memiliki daun berwarna merah keperakan dan mengkilap ketika terkena cahaya. Seiring perkembangan zaman, ramai dibicarakan mengenai manfaat tanaman obat. Sirih merah memiliki kandungan senyawa aktif seperti minyak atsiri, alkaloid, saponin, tanin dan flavonoid ${ }^{1}$. Minyak atsiri yang terkandung di dalamnya memiliki aktivitas sebagai antiseptik. Infusa daun sirih merah juga memiliki kemampuan untuk menyembuhkan luka perineum dengan total hari perawatan yang lebih sedikit dibandingkan dengan betadin ${ }^{2}$. Penelitian yang dilakukan oleh Tonahi et $a /^{3}$ menyebutkan bahwa ekstrak etanol daun sirih merah memiliki aktivitas antioksidan dengan aktivitas penghambatan radikal bebas sebesar $81,82 \%$ dan dengan $\mathrm{IC}_{50}$ sebesar 47,45 $\mathrm{ppm}^{3}$.

Tanaman lain yang juga memiliki banyak manfaat adalah kayu manis. Minyak kayu manis diketahui memiliki aktivitas sebagai anti inflamasi; ${ }^{4 ; 5}$. Komponen senyawa yang terdapat dalam tanaman ini seperti sinamaldehid, eugenol, arabinoksilan, 2-hidroksinamaldehid, 2-benzoloksimaldehid ${ }^{6}$. Kombinasi dari kedua bahan alam ini menjadi hal yang dapat dipertimbangkan untuk meningkatkan efektifitas dalam penggunaannya. sirih merah dan minyak kayu manis maka perlu dilakukan pengembangan sediaan farmasi yang aman, mudah digunakan dan nyaman dalam pengaplikasian secara topikal. Gel adalah sediaan topikal yang paling digemari karena bersifat sejuk, melembabkan dan mudah dalam penggunaan.

Sedian gel berpotensi lebih baik sebagai sarana untuk mengelola obat topikal dibandingkan dengan salep, karena sifat gel yang tidak lengket, stabil, memiliki nilai estetika yang baik, dan tidak memerlukan energi yang besar untuk formulasi. Sediaan gel yang baik dapat diperoleh dengan memformulasikan beberapa jenis bahan pembentuk gel, namun yang terpenting adalah pemilihan gelling agent $^{7}$. Berdasarkan uraian diatas maka 
pada penelitian ini dilakukan formulasi gel kombinasi esktrak sirih merah dan minyak kayu manis dengan menggunakan HPMC (Hidroksipropil metilselulosa) sebagai gelling agent dan dilakukan evaluasi sifat fisik gel (homogenitas, organoleptik, uji daya lekat, uji daya sebar, $\mathrm{pH}$, dan konsistensi).

\section{METODE PENELITIAN}

\section{Alat dan Bahan}

Alat yang digunakan pada penelitian ini adalah maserator, Rotary evaporator/ waterbath, Kain flanel, Cawan porselen, Mortir dan stamper, alat-alat gelas, jangka sorong, objek glass, Alat uji daya lekat, Sentrifugator, kaca bulat berdiameter, viskosimeter, pH universal. Bahan yang digunakan pada penelitian ini antara lain minyak kayu manis, sirih merah (Piper crocatum Var. Rubrum), Pelarut etanol 70\%, HPMC (Hydroxyprophylmethilcelulose), propilen glikol, metil paraben.

\section{Rancangan Penelitian}

Desain penelitian ini adalah eksperimental laboratorium. Kegiatan yang dilakukan adalah pembuatan ekstrak etanol daun sirih merah, pembuatan sediaan gel kombinasi ekstrak etanolik daun sirih merah dan kayu manis kemudian dilanjutkan dengan uji sifat fisik sediaan gel meliputi uji organoleptik, uji homogenitas, uji pH, uji daya sebar, uji daya lekat, uji viskositas dan uji konsistensi.

\section{Pembuatan ekstrak etanolik daun sirih merah (Piper var. Rubrum)}

Pembuatan ekstrak etanolik daun sirih merah dilakukan dengan metode maserasi yaitu dengan perendaman. Daun sirih merah yang akan digunakan dibersihkan dan dikeringkan kemudian dihaluskan hingga menjadi serbuk. Sejumlah $1 \mathrm{~kg}$ serbuk daun sirih merah direndam selama 24 jam dengan $10 \mathrm{~L}$ etanol, kemudian disaring dan diuapkan diatas waterbath hingga terbentuk ekstrak yang kental. Ekstrak kental yang diperoleh lalu dihitung rendemennya ${ }^{8}$.

\section{Pembuatan Sediaan Gel Kombinasi Ekstrak Etanol Daun Sirih Merah dan Kayu Manis}

Formulasi sediaan gel kombinasi ekstrak etanol daun sirih merah dan kayu manis sebagai berikut: 
Formulasi dan Uji Sifat Fisik Sediaan Gel Tunggal dan Kombinasi Ekstrak Etanolik Daun Sirih Merah (Pipper Crocatum) dan Minyak Kayu Manis (Cinnamon Oil)

Tabel I. Formulasi sediaan Gel Kombinasi Ekstrak Etanol Daun Sirih Merah dan Kayu Manis (Yusuf et al., 2017)

\begin{tabular}{llccccc}
\hline \multirow{2}{*}{ No } & \multirow{2}{*}{ Nama Bahan } & FI & FII & FIII & FIV & \multirow{2}{*}{ Keterangan } \\
\cline { 3 - 6 } & & 20 & - & 20 & 40 & Zat Aktif \\
\hline 1 & Ekstrak daun sirih merah (\%) & - & 4 & 2 & 4 & Zat Aktif \\
2 & Minyak Kayu Manis (ml) & 2 & 2 & 2 & 2 & Basis Gel \\
3 & HPMC (\%) & 6 & 6 & 6 & 6 & Pelembab \\
4 & Propilen glikol (g) & 0,2 & 0,2 & 0,2 & 0,2 & Pengawet \\
5 & Metil Paraben (\%) & 50 & 50 & 50 & 50 & Pembawa \\
6 & Aquadest ad (g) & & & & & \\
\hline
\end{tabular}

Pembuatan sediaan gel dengan menggunakan metode dingin. Sejumlah basis HPMC dilarutkan dalam akuades dan didiamkan selama 24 jam sampai mengembang dan diaduk secara homogen hingga terbentuk massa gel. Metil paraben dilarutkan dalam sedikit etanol. Ekstrak daun sirih merah dan minyak kayu manis kemudian ditambahkan propilen glikol sedkit demi sedikit dan diaduk hingga homogen. Gel yang terbentuk kemudian dicukupkan dengan akuadest hingga 50gram dan diaduk hingga membentuk massa gel yang homogen.

\section{Pengujian Sifat Fisik Sediaan Gel Kombinasi Ekstrak Etanolik Daun Sirih Merah dan Kayu Manis}

\section{Uji Organoleptis}

Uji organoleptis pada sediaan gel dilakukan dengan mengamati warna, bau dan bentuk dari sediaan tersebut ${ }^{9}$.

\section{Uji Homogenitas}

Uji homogenitas dilakukan dengan cara gel kombinasi ekstrak etanolik daun sirih merah dan kayu manis dioleskan pada gelas objek kemudian diamati apakah warna merata atau tidak terdapat butir-butir halus ${ }^{9}$.

\section{Uji pH}

Uji pH dilakukan dengan menggunakan $\mathrm{pH}$ universal. Kertas $\mathrm{pH}$ dimasukkan ke dalam sediaan gel dan ditunggu kurang lebih 1 menit kemudian diangkat dan disesuaikan berdasarkan $\mathrm{pH}$ standar universal ${ }^{10}$. 


\section{Uji Daya Sebar}

Uji daya sebar dilakukan dengan mengambil sejumlah 0,5gram sediaan gel dan diletakkan ditengah kaca bulat yang telah diberikan skala. Kemudian ditutup dengan kaca sebagai beban awal dan didiamkan selama 1 menit. Setelah 1 menit diameter daya sebar diukur. Beban kemudian ditambahkan lagi 50gram dan didiamkan kembali selama 1 menit dan dilakukan pengukuran yang sama seperti sebelumnya setiap penambahan 50gram beban sampai 250 gram $^{10}$.

\section{Uji Daya Lekat}

Uji daya lekat dilakukan dengan mengambil sejumlah 0,25gram salep yang diletakkan pada kaca objek dan kemudian ditutup dengan kaca objek yang lain. Kaca objek ditekan dengan beban berat $1 \mathrm{~kg}$ selama 5 menit. Beban kemudian diangkat dan kaca objek dipasang pada alat uji daya lekat. Alat uji diberi beban 80 gram kemudian dicatat waktu pelepasan gel antara 2 kaca objek tersebut ${ }^{9}$.

\section{HASIL DAN PEMBAHASAN}

\section{Ekstraksi Daun Sirih Merah}

Metode ekstraksi yang digunakan pada penelitian ini adalah maserasi yaitu dengan merendam serbuk sirih merah dalam pelarut yang sesuai selama 24 jam dan dilakukan proses remaserasi. Serbuk sirih merah (Piper crocatum Ruiz \& Pav) yang diekstraksi sebanyak 500gram dalam 5 L etanol 70\% diperoleh berat ekstrak kental sebanyak 169, 84gram dan rendemen sebesar $33,968 \%$.

\section{Pembuatan Gel dan Pengujian SIfat Fisik Sediaan Gel Kombinasi Ekstrak Etanolik Daun}

\section{Sirih Merah dan Kayu Manis}

Metode yang digunakan dalam pembuatan sediaan gel adalah dengan metode dingin menggunakan HPMC (Hidroksipropilmetilselulosa) sebagai basis, propilen glikol sebagai pelembab, metil paraben sebagai pengawet dan ekstrak etanolik daun sirih merah serta minyak kayumanis sebagai zat aktif. Basis gel HPMC merupakan basis yang biasa digunakan pada formulasi sediaan kosmetika maupun obat karena basis ini dapat menghasilkan gel yang bening, mudah larut dalam air dan memiliki tingkat ketoksikan yang rendah. Selain itu basis ini mempunyai pH yang stabil, tahan terhadap asam basa, mikroba dan panas 
Formulasi dan Uji Sifat Fisik Sediaan Gel Tunggal dan Kombinasi Ekstrak Etanolik Daun Sirih Merah (Pipper Crocatum) dan Minyak Kayu Manis (Cinnamon Oil)

(10). Basis Gel HPMC memiliki kemampuan daya sebar yang baik jika dibandingkan dengan carbophol dan metilselulosa ${ }^{12}$.

\section{Uji Organoleptis}

Uji organoleptis dilakukan secara visual pada suhu kamar, dengan cara mengamati bentuk, bau, dan warna. Hasil pengamatan dari uji organoleptis dapat dilihat pada tabel II. Bentuk dari sediaan gel berupa kental, semi padat. Pengamatan warna sediaan gel formula 1 memiliki warna putih tulang karena hanya menggunakan zat aktif minyak kayu manis (Cinnamon oil), formula 2 memiliki warna hijau pekat karena ada penambahan ekstrak sirih merah (Piper crocatum Ruiz \& Pav), formula 3 berwarna hijau pekat dan formula 4 berwarna hijau pekat cenderung hitam karena jumlah konsentrasi ekstrak lebih banyak Hasil dari formulasi gel kombinasi ekstrak etanolik Daun sirih merah dan kayu manis dapat dilihat pada gambar 1.

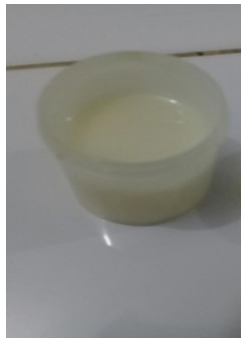

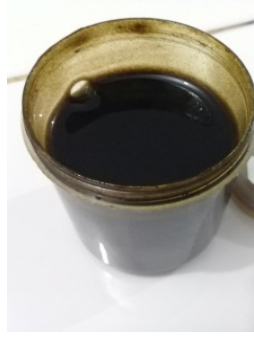

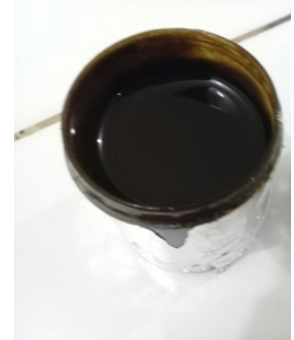

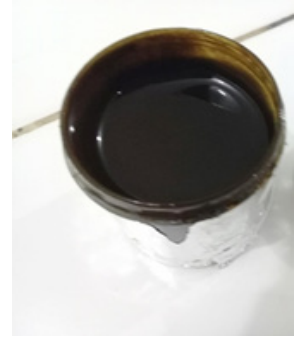

Gambar 1. Hasil Formulasi sediaan gel tunggal dan kombinasi dari Ekstrak etanolik daun sirih merah dan minyak kayu manis

Keterangan :

1 : Formulasi gel ekstrak sirih merah $20 \%$

2 : Formulasi gel minyak kayu manis $4 \mathrm{~mL}$

3 : Formulasi Gel kombinasi sirih merah $20 \%$ dan minyak kayu manis $2 \mathrm{ml}$

4 : Formulasi Gel Kombinasi Sirih Merah 40\% dan minyak kayu manis $4 \mathrm{ml}$

Tabel II. Hasil Uji Organoleptis Sediaan Gel tunggal dan Kombinasi Ekstrak Etanolik Daun Sirih Merah dan Kayu Manis

\begin{tabular}{ccccc}
\hline No & Formula & Bentuk & Warna & Bau \\
\hline $\mathbf{1}$ & I & Kental, semi padat & Putih tulang & Bau khas kayu manis \\
$\mathbf{2}$ & II & Kental, semi padat & Hijau pekat & Bau khas sirih merah \\
$\mathbf{3}$ & III & Kental, semi padat & Hiijau pekat & Bau khas kayu manis lebih dominan \\
$\mathbf{4}$ & IV & Kental, semi padat & $\begin{array}{c}\text { Hijau pekat, } \\
\text { cenderung hitam }\end{array}$ & Bau khas kayu manis lebih dominan \\
\hline
\end{tabular}


Keterangan :

Formula I : Formulasi gel ekstrak sirih merah $20 \%$

Formula II : Formulasi gel minyak kayu manis $4 \mathrm{~mL}$

Formula III : Formulasi Gel kombinasi sirih merah 20\% dan minyak kayu manis $2 \mathrm{ml}$

Formula IV : Formulasi Gel Kombinasi Sirih Merah 40\% dan minyak kayu manis $4 \mathrm{ml}$

\section{Uji Homogenitas}

Pengujian pada formula 1, 2, 3 dan 4 menunjukkan bahwa sediaan gel kombinasi minyak kayu manis (Cinnnamon oil) dan sirih merah (Piper crocatum Ruiz \& Pav) terdapat persamaan warna dan tidak terdapat partikel atau butiran kasar pada sediaan, sehingga sediaan gel dapat dikatakan homogen dan telah memenuhi persyaratan untuk diformulasikan. Hasil uji homogenitas sediaan dapat dilihat pada tabel III.

Tabel III. Hasil Uji Homogenitas Sediaan Gel Tunggal dan Kombinasi Ekstrak Etanolik Daun Sirih Merah dan Minyak Kayu Manis

\begin{tabular}{cccc}
\hline \multirow{2}{*}{ No } & Formula & Ya & Homogen \\
\cline { 3 - 4 } & & & Tidak \\
\hline 1 & Formula I & & - \\
2 & Formula II & & - \\
3 & Formula III & & - \\
4 & Formula IV & & \\
\hline
\end{tabular}

Keterangan :

Formula I : Formulasi gel ekstrak sirih merah $20 \%$

Formula II : Formulasi gel minyak kayu manis $4 \mathrm{~mL}$

Formula III : Formulasi Gel kombinasi sirih merah $20 \%$ dan minyak kayu manis $2 \mathrm{ml}$

Formula IV : Formulasi Gel Kombinasi Sirih Merah 40\% dan minyak kayu manis $4 \mathrm{ml}$

Uji pH

Pengujian pH pada sediaan gel kombinasi minyak kayu manis (Cinnamon oil) dan sirih merah (Piper crocatum Ruiz \& Pav) bertujuan untuk mengetahui apakah sediaan sudah sesuai dengan $\mathrm{pH}$ kulit. Pengujian $\mathrm{pH}$ ini sangat penting karena jika $\mathrm{pH}$ terlalu basa maka akan menyebabkan kulit kering dan gatal, dan jika pH terlalu asam maka akan menyebabkan iritasi pada kulit(13). Hasil pengamatan uji pH dapat dilihat pada tabel IV.

Tabel IV. Hasil Uji pH Sediaan Gel Tunggal dan Kombinasi Ekstrak Etanolik Daun Sirih Merah dan Minyak Kayu Manis

\begin{tabular}{ccc}
\hline No & Formula & pH \\
\hline I & Formula 1 & 5 \\
II & Formula 2 & 5 \\
III & Formula 3 & 6 \\
IV & Formula 4 & 6 \\
\hline
\end{tabular}


Formulasi dan Uji Sifat Fisik Sediaan Gel Tunggal dan Kombinasi Ekstrak Etanolik Daun Sirih Merah (Pipper Crocatum) dan Minyak Kayu Manis (Cinnamon Oil)

Keterangan :

Formula I : : Formulasi gel ekstrak sirih merah $20 \%$

Formula II : Formulasi gel minyak kayu manis $4 \mathrm{~mL}$

Formula III : Formulasi Gel kombinasi sirih merah 20\% dan minyak kayu manis $2 \mathrm{ml}$

Formula IV : Formulasi Gel Kombinasi Sirih Merah 40\% dan minyak kayu manis $4 \mathrm{ml}$

\section{Uji Daya Sebar}

Tujuan dari uji daya sebar ini adalah untuk mengetahui seberapa baik sediaan gel yang menyebar ke permukaan kulit, karena dapat mempengaruhi absorbsi obat dan kecepatan pelepasan zat aktif pada tempat pemakaian (14). Kemampuan penyebaran yang baik akan memberikan kemudahan ketika pengaplikasian di permukaan kulit, penyebaran zat aktif pada kulit menjadi lebih merata sehingga efek yang ditimbulkan oleh bahan aktif yang ada dalam sediaan gel menjadi lebih optimal (14). Hasil pengamatan uji daya sebar dapat dilihat pada tabel V, berdasarkan hasil pengamatan gel minyak kayu manis (Cinnamon oil) tunggal, sirih merah tunggal (Piper crocatum Ruiz \& Pav) tunggal, kombinasi dengan konsentrasi 20\%, kombinasi dengan konsentrasi $40 \%$ mempunyai daya sebar yang sesuai dengan persyaratan untuk sediaan topikal yaitu $5-7 \mathrm{~cm}(15)$.

Tabel V. Hasil Uji Daya Sebar Sediaan Gel Tunggal dan Kombinasi Ekstrak Etanolik Daun Sirih Merah dan Minyak Kayu Manis

\begin{tabular}{ccc}
\hline NO & FORMULA & DIAMETER \\
\hline $\mathbf{1}$ & Formula I & $5,6 \mathrm{~cm}$ \\
$\mathbf{2}$ & Formula II & $5 \mathrm{~cm}$ \\
$\mathbf{3}$ & Formula III & $5 \mathrm{~cm}$ \\
$\mathbf{4}$ & Formula IV & $5,5 \mathrm{~cm}$ \\
\hline
\end{tabular}

Keterangan :

Formula I : Formulasi gel ekstrak sirih merah 20\%

Formula II : Formulasi gel minyak kayu manis $4 \mathrm{~mL}$

Formula III : Formulasi Gel kombinasi sirih merah 20\% dan minyak kayu manis $2 \mathrm{ml}$

Formula IV : Formulasi Gel Kombinasi Sirih Merah 40\% dan minyak kayu manis $4 \mathrm{ml}$

\section{Uji Daya Lekat}

Daya lekat gel dapat mempengaruhi efektifitas penyembuhan inflamasi, semakin lama gel melekat maka semakin banyak juga pelepasan zat aktifnya. Hasil pengamatan uji daya lekat dapat dilihat pada tabel VI, dari semua formula uji gel minyak kayu manis (Cinnnamon oil) dan sirih merah (Piper crocatum Ruiz \& Pav) hasilnya memenuhi persyaratan karena daya 
lekatnya lebih dari 1 detik (16). Hasil penelitian yang dilakukan diketahui bahwa semakin besar konsentrasi ekstrak yang ditambahkan, semakin lama pula daya lekatnya.

Tabel VI. Hasil Uji Daya Lekat Sediaan Gel kombinasi Ekstrak Etanolik Daun Sirih Merah dan Minyak Kayu Manis

\begin{tabular}{ccc}
\hline NO & FORMULA & DAYA LEKAT \\
\hline $\mathbf{1}$ & Formula I & 10,64 (detik) \\
$\mathbf{2}$ & Formula II & 20,14 (detik) \\
$\mathbf{3}$ & Formula III & 09,74 (detik) \\
$\mathbf{4}$ & Formula IV & 02,02 (menit) \\
\hline
\end{tabular}

Keterangan :

Formula I : : Formulasi gel ekstrak sirih merah $20 \%$

Formula II : : Formulasi gel minyak kayu manis $4 \mathrm{~mL}$

Formula III : Formulasi Gel kombinasi sirih merah 20\% dan minyak kayu manis $2 \mathrm{ml}$

Formula IV : Formulasi Gel Kombinasi Sirih Merah $40 \%$ dan minyak kayu manis $4 \mathrm{ml}$

\section{Uji Konsistensi}

Uji konsistensi bertujuan untuk mengetahui stabilitas dari sediaan gel yang dibuat. Dari hasil uji konsistensi dari semua formula, baik formula tunggal maupun kombinasi menunjukkan tidak terjadi pemisahan setelah gel tersebut di sentifus selama 5 jam. Hasil uji konsistensi dapat dilihat pada tabel VII.

Tabel VII. Hasil Uji Konsistensi Sediaan Gel Tunggal dan Kombinasi Ekstrak Etanolik Daun Sirih Merah dan Minyak Kayu Manis

\begin{tabular}{cccc}
\hline NO & FORMULA & Ya & Pemisahan \\
\cline { 3 - 4 } 1 & Formula 1 & - & \\
2 & Formula 2 & - & \\
3 & Formula 3 & - & \\
4 & Formula 4 & - & \\
\hline
\end{tabular}

Keterangan :

Formula I : : Formulasi gel ekstrak sirih merah $20 \%$

Formula II : Formulasi gel minyak kayu manis $4 \mathrm{~mL}$

Formula III : Formulasi Gel kombinasi sirih merah 20\% dan minyak kayu manis $2 \mathrm{ml}$

Formula IV : Formulasi Gel Kombinasi Sirih Merah 40\% dan minyak kayu manis $4 \mathrm{ml}$

\section{KESIMPULAN DAN SARAN}

\section{Kesimpulan}

Sediaan gel kombinasi ekstrak etanolik daun sirih merah dan minyak kayu manis memenuhi persyaratan sifat fisik sediaan gel, meliputi organoleptis, homogenitas, $\mathrm{pH}$, daya lekat dan daya sebar, dan konsistensi 
Emelda, Emelda

Formulasi dan Uji Sifat Fisik Sediaan Gel Tunggal dan Kombinasi Ekstrak Etanolik Daun Sirih Merah

(Pipper Crocatum) dan Minyak Kayu Manis (Cinnamon Oil)

\section{Saran}

Perlu dilakukan penelitian lebih lanjut mengenai pengaruh gelling agent terhadap sifat fisik sediaan gel kombinasi ekstrak etanolik daun sirih merah dan kayu manis.

\section{DAFTAR PUSTAKA}

1. Andareto. (2015). Apotik herbal di sekitar anda. Pustaka ilmu semesta.

2. Damarini, S., Eliana, E., \& Mariati, M. (2013). Efektivitas Sirih Merah dalam Perawatan Luka Perineum di Bidan Praktik Mandiri. Kesmas: National Public Health Journal, 8(1), 39. https://doi.org/10.21109/kesmas.v8i1.340

3. Tonahi, J., Nuryanti, S., \& Suherman, S. (2014). Antioksidan dari Daun Sirih Merah (Piper Crocatum). Jurnal Akademika Kimia, 3(3), 158-164.

4. Han, X., \& Parker, T. L. (2017). Antiinflammatory Activity of Cinnamon (Cinnamomum zeylanicum) Bark Essential Oil in a Human Skin Disease Model. Phytotherapy Research, 31(7), 1034-1038. https://doi.org/10.1002/ptr.5822

5. Joshi, K., Awte, S., Bhatnagar, P., Walunj, S., Gupta, R., Joshi, S., Sabharwal, S., Bani, S., \& Padalkar, a. S. (2010). Cinnamomum zeylanicum extract inhibits proinflammatory cytokine TNF $\mu$ : in vitro and in vivo studies. Research in Pharmaceutical Biotechnology, 2(2), 14-21. http://www.academicjournals. org/journal/RPB/article-abstract/4901513455

6. Anggraini, A. R., \& Oliver, J. (2019). Uji Aktivitas Anti Inflamasi Topikal Fraksi Etil Asetat Dari Ekstrak Metanol Daun Sirih Merah (Piper crocatum Ruiz \& Pav. Pada Mencit Diinduksi Karagenin. Journal of Chemical Information and Modeling, 53(9), 1689-1699. https://doi.org/10.1017/СВ09781107415324.004

7. Wulandari, E. T., \& Kumalasari, D. (2017). Herbal untuk Perawatan Masa Nifas: Penggunaan Kayu Manis untuk Nyeri Perineum dan Luka Episiotomi. Aisyah: Jurnal Ilmu Kesehatan, (2)(2), 93-98.

8. Emelda. (2017). Potensi Tongkat Ali (Eurycoma longifolia Jack.) Sebagai Anti Inflamasi; Journal of Current Pharmaceutical Sciences. https://www.journal. umbjm.ac.id/index. php/jcps/article/view/78

9. Arista, Y., Kumesan, N., Yamlean, P. V. Y., \& Supriati, H. S. (2013). Formulasi Dan Uji Aktivitas Gel Antijerawat Ekstrak Umbi Bakung (Crinum Asiaticum L.) Terhadap Bakteri Staphylococcus Aureus Secara in Vitro. PHARMACON Jurnal IImiah Farmasi - UNSRAT, 2(02), 2302-2493.

10. Azzahra, F., Prastiwi, H., \& Solmaniati. (2019). Formulasi dan Uji Sifat Fisik Sediaan Krim dan Salep Ekstrak Etanol Daun Pare (Momordica charantia L.). Akfarindo, 4(1), 1-7.

11. Yusuf, A. L., Nurawaliah, E., \& Harun, N. (2017). Uji efektivitas gel ekstrak etanol daun kelor (Moringa oleifera L.) sebagai antijamur Malassezia furfur. Kartika : Jurnal Ilmiah Farmasi, 5(2), 62. https://doi.org/10.26874/kjif.v5i2.119

12. Singh, M., Nagori, B., \& ... N. S. (2013). Formulation development \&evaluation of topical gel formulations using different gelling agents and its comparison with marketed gel formulation. International Journal of Pharmaceutical Erudition, 3(3), 1-10.

13. Tranggono, R., Utama, F. L.-J. P. G. P., \& 2007, U. (2007). Buku pegangan ilmu pengetahuan kosmetik.

14. Riska. (2017). Formulasi Sediaan Gel Kombinasi Ekstrak Daun Sirih Merah (Piper crocatum Ruiz. and Pav.) dan Ekstrak Herba Pegagan (Centella asiatica (L.) Urban) Dengan Variasi Carbopol 940 Sebagai Gelling Agent; Repository Poltekkes Kemenkes Palembang. https:// repository.poltekkespalembang.ac.id/items/show/376 
Formulasi dan Uji Sifat Fisik Sediaan Gel Tunggal dan Kombinasi Ekstrak Etanolik Daun Sirih Merah (Pipper Crocatum) dan Minyak Kayu Manis (Cinnamon Oil)

15. Novaritasari, I., Ariesti, N., \& Sunnah, I. (2014). UjiEfektifitas Formulasi Gel Perasan Umbi Kentang (Solanum tuberosum L.) Terhadap Lama Kesembuhan Luka Bakar pada Kelinci (Oryctolagus.)

16. Lisa, M. (2009). Pengaruh Konsentrasi Minyak Atsiri Kencur (Kaempferia galanga L.) Dengan Basis Salep Larut Air Terhadap Sifat Fisik Salep dan Daya Hambat Bakteri Staphylococcus aureus Secara In Vitro; SKRIPSI [Universitas Muhammadiyah Surakarta]. http://eprints.ums.ac.id/id/eprint/3269 